\title{
Myroides marinus sp. nov., a member of the family Flavobacteriaceae, isolated from seawater
}

Correspondence Seung Bum Kim sbk01@cnu.ac.kr

\section{Sung-Heun Cho, ${ }^{1}$ Song-Hee Chae, ${ }^{1}$ Wan-Taek Im $^{2}$ and Seung Bum Kim ${ }^{1}$}

\author{
${ }^{1}$ Department of Microbiology and Molecular Biology, School of Bioscience and Biotechnology, \\ Chungnam National University, 220 Gung-dong, Yuseong, Daejeon 305-764, Republic of Korea \\ ${ }^{2}$ Department of Biological Sciences, Korea Advanced Institute of Science and Technology, 373-1 \\ Guseong-dong, Yuseong-gu, Daejeon 305-701, Republic of Korea
}

\begin{abstract}
A Gram-negative, aerobic, non-motile, yellow-pigmented, rod-shaped bacterium (strain JS-08 ${ }^{\top}$ ) isolated from seawater was subjected to a polyphasic taxonomic study. 16S rRNA gene sequence analysis indicated that strain $\mathrm{JS}^{-08^{\top}}$ belongs to the genus Myroides, a member of the phylum Bacteroidetes. Its closest phylogenetic relative was Myroides odoratimimus JCM 7460', with which it shared $97.0 \% 16$ S RNA gene sequence similarity. Strain JS-08 ${ }^{\top}$ contained menaquinone-6 (MK-6) as the predominant menaquinone, and the dominant fatty acids were iso- $\mathrm{C}_{15: 0}$, iso- $\mathrm{C}_{17: 0} 3-\mathrm{OH}$ and a summed feature consisting of iso- $\mathrm{C}_{15: 0} 2-\mathrm{OH}$ and/or $\mathrm{C}_{16: 1} \omega 7 \mathrm{c}$. The DNA G+C content of strain JS-08 ${ }^{\top}$ was $34.2 \mathrm{~mol} \%$. Based on phenotypic, genotypic and phylogenetic evidence, it is suggested that strain $\mathrm{JS}-08^{\top}$ represents a novel species of the genus Myroides, for which the name Myroides marinus sp. nov. is proposed. The type strain is $\mathrm{JS}-08^{\top}\left(=\mathrm{KCTC} 23023^{\top}=\mathrm{JCM} 16529^{\top}\right)$.
\end{abstract}

The genus Myroides, belonging to the family Flavobacteriaceae (Bernardet et al., 2002), was first described with the reclassification of Flavobacterium odoratum strains as Myroides odoratus and Myroides odoratimimus based on a polyphasic approach (Vancanneyt et al., 1996). At the time of writing, the genus Myroides comprised four recognized species, namely $M$. odoratus, $M$. odoratimimus (Vancanneyt et al., 1996), M. pelagicus (Yoon et al., 2006) and M. profundi (Zhang et al., 2008).

Strains of Myroides have been found in various terrestrial and aquatic environments. Most strains of M. odoratus and M. odoratimimus have been isolated from clinical specimens (Holmes et al., 1977), whereas those of the other species have been isolated from the marine environment (Yoon et al., 2006; Zhang et al., 2008), freshwater fish (González et al., 2000) and the insect gut (Spiteller et al., 2000).

A number of studies have focused on Myroides strains as causative agents in various infections (Bachmeyer et al., 2008; Douce et al., 2008; Green et al., 2001; Källman et al., 2006; Thomas et al., 2007; Yağci et al., 2000). Attention has also been given to strains belonging to Myroides because novel types of metalloenzymes have been reported from various species of the genus (Chen et al., 2009; Mammeri et al., 2002) and biosurfactant compounds have been isolated from strains of M. pelagicus (Maneerat et al., 2005,

The GenBank/EMBL/DDBJ accession number for the 16S rRNA gene sequence of strain $\mathrm{JS}^{-08^{\top}}$ is GQ857652.
2006). These reports clearly indicate the wide distribution of members of the genus Myroides in nature and their potential as a source of industrially useful compounds, yet the diversity within the genus remains to be fully unravelled. In the present study, we report the description of a novel Myroides species isolated during a culturedependent study of halophilic bacterial diversity associated with marine environments. The taxonomic status of the organism was determined by using a polyphasic approach.

Strain JS- $08^{\mathrm{T}}$ was originally isolated by using the standard dilution plating technique on marine agar 2216 (MA; Difco) from seawater collected off Boryeong Province, Chungnam, Republic of Korea. Examination of the morphological and biochemical properties of strain JS$08^{\mathrm{T}}$ followed previously described procedures (Yoon et al., 2006; Zhang et al., 2008). The following phenotypic tests were performed: Gram stain, cell morphology, catalase and oxidase activities and hydrolysis of casein, cellulose, DNA, starch, Tweens 20, 40, 60 and 80 and urea. Growth at 4, 10, $20,25,30,37$ and $42{ }^{\circ} \mathrm{C}$ and at $\mathrm{pH} 4-12$ (at intervals of 1.0 $\mathrm{pH}$ unit, adjusted by using $1 \mathrm{M} \mathrm{HCl}$ or $\mathrm{NaOH}$ ) was examined in marine broth (Difco). Growth in the presence of $0,3,5,10,15$ and $20 \% \mathrm{NaCl}$ was investigated by using a basal medium containing (per litre) $10 \mathrm{~g}$ peptone and $5 \mathrm{~g}$ yeast extract. Other biochemical and physiological properties were examined by using API 20E and API ZYM strips (bioMérieux) according to the manufacturer's instructions. Utilization of 95 selected carbon sources was examined by using Biolog GN2 microplates according to the manufacturer's instructions. 
The isoprenoid quinone content was analysed via reversedphase HPLC as described by Cho et al. (2008). Analysis of fatty acid methyl esters was carried out according to the standard protocol of the Microbial Identification System (Microbial ID) (Kämpfer \& Kroppenstedt, 1996). The DNA $\mathrm{G}+\mathrm{C}$ content was determined by using the methods outlined by Cui et al. (2007).

The $16 \mathrm{~S}$ rRNA gene of strain JS- $08^{\mathrm{T}}$ was amplified by PCR from genomic DNA and sequenced as described previously (Cho et al., 2008). The resultant 16S rRNA gene sequence was aligned with corresponding sequences of the type strains of recognized Myroides species by using the PHYDIT program, version 3.1 (http://plaza.snu.ac.kr/ jchun/phydit/). Phylogenetic trees were inferred by using the Fitch-Margoliash, maximum-likelihood, maximum-parsimony and neighbour-joining methods following procedures described previously (Kim et al., 2003).

Strain JS- $08^{\mathrm{T}}$ formed yellow-to-orange, circular, convex colonies with entire margins on MA at $30{ }^{\circ} \mathrm{C}$ within $48 \mathrm{~h}$. Growth occurred at $10-37{ }^{\circ} \mathrm{C}$. Cells were aerobic, Gramnegative, non-spore-forming, non-motile rods. Other phenotypic characteristics are given in the species description and in Table 1. Strain JS- $08^{\mathrm{T}}$ could be readily distinguished phenotypically from recognized species of the genus Myroides. Notably, the novel strain was in general positive for more enzyme activities and had a wider carbon source utilization spectrum, implying that strain JS- $08^{\mathrm{T}}$ had a wider metabolic capability than the representative Myroides strains investigated.

Menaquinone-6 (MK-6) was the predominant quinone isoprenologue. Strain JS- $08^{\mathrm{T}}$ contained iso- $\mathrm{C}_{15: 0}(24.2 \%$ of the total fatty acid composition), iso- $\mathrm{C}_{17: 0} 3-\mathrm{OH}$ $(18.1 \%)$ and a summed feature consisting of iso- $\mathrm{C}_{15: 0}$ $2-\mathrm{OH}$ and/or $\mathrm{C}_{16: 1} \omega 7 c(16.8 \%)$ as the predominant fatty acids. Table 2 shows the detailed fatty acid profile of strain $\mathrm{JS}-08^{\mathrm{T}}$ in comparison with those of recognized Myroides species. The presence of $\mathrm{C}_{18: 1} \omega 6 c(1.8 \%)$ and $\mathrm{C}_{17: 0} 3-\mathrm{OH}$ $(1.3 \%)$ was characteristic of strain JS- $08^{\mathrm{T}}$. The DNA G $+\mathrm{C}$ content of strain JS- $08^{\mathrm{T}}$ was $34.2 \mathrm{~mol} \%$, within the range reported for the genus $(33.8-36.7 \mathrm{~mol} \%$ ).

Phylogenetic analysis based on $16 \mathrm{~S}$ rRNA gene sequences revealed that strain $J S-08^{\mathrm{T}}$ is a member of the family Flavobacteriaceae and forms a coherent cluster with species of the genus Myroides (Fig. 1). Strain JS- $08^{\mathrm{T}}$ was related

Table 1. Differential phenotypic characteristics between strain JS-08 ${ }^{\top}$ and the type strains of recognized Myroides species

Strains: 1, JS- $08^{\mathrm{T}}$; 2, M. odoratimimus JCM $7460^{\mathrm{T}} ; 3$, M. profundi DSM $19823^{\mathrm{T}}$; 4, M. pelagicus KCTC $12661^{\mathrm{T}}$; 5, M. odoratus JCM $7458^{\mathrm{T}}$. Data for source of isolation and DNA G +C content values in parentheses were taken from previous studies (Vancanneyt et al., 1996; Yoon et al., 2006; Zhang et al., 2008); other data were obtained in this study.

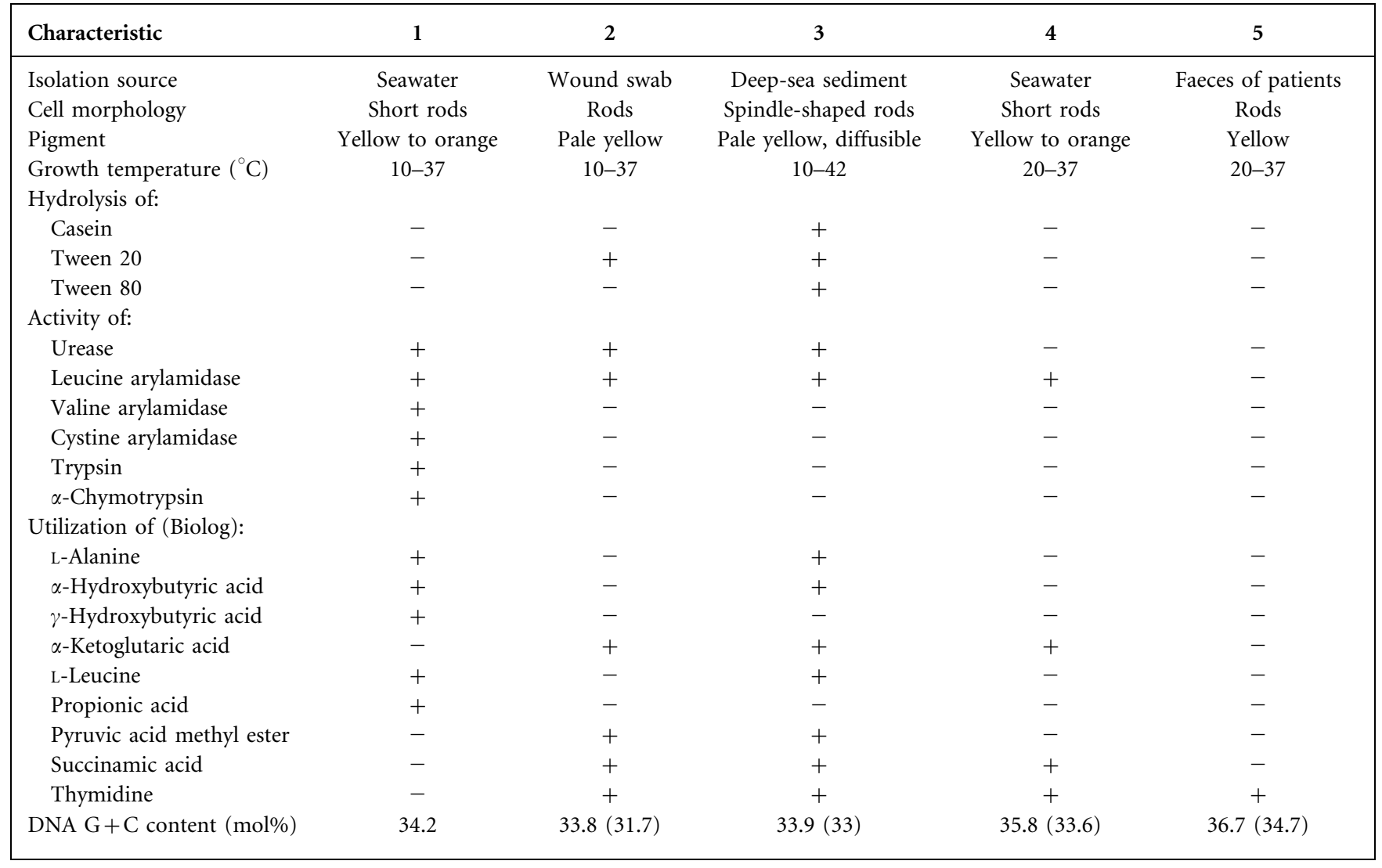


Table 2. Fatty acid contents of strain $\mathrm{JS}-08^{\top}$ and the type strains of recognized Myroides species

Strains: 1 , JS $-08^{\mathrm{T}} ; 2$, M. odoratimimus JCM $7460^{\mathrm{T}} ; 3$, M. profundi DSM $19823^{\mathrm{T}}$; 4, M. pelagicus KCTC $12661^{\mathrm{T}}$; 5, M. odoratus JCM $7458^{\mathrm{T}}$. Data were obtained in this study and are percentages of total fatty acids. -, Less than $1.0 \%$ of the total or not detected.

\begin{tabular}{|c|c|c|c|c|c|}
\hline Fatty acid & 1 & 2 & 3 & 4 & 5 \\
\hline \multicolumn{6}{|l|}{$\begin{array}{l}\text { Straight-chain } \\
\text { saturated }\end{array}$} \\
\hline $\mathrm{C}_{16: 0}$ & 1.3 & 1.4 & 1.3 & - & - \\
\hline \multicolumn{6}{|l|}{ Branched saturated } \\
\hline iso- $\mathrm{C}_{13: 0}$ & - & 2.0 & 1.0 & 1.0 & - \\
\hline iso- $\mathrm{C}_{14: 0}$ & 2.6 & 1.5 & 1.7 & 3.3 & - \\
\hline iso- $\mathrm{C}_{15: 0}$ & 24.2 & 44.7 & 27.6 & 29.3 & 43.7 \\
\hline anteiso- $\mathrm{C}_{15: 0}$ & 1.1 & 3.8 & - & - & 8.1 \\
\hline iso- $\mathrm{C}_{16: 0}$ & 3.4 & 2.7 & 4.3 & 8.7 & 1.2 \\
\hline iso- $\mathrm{C}_{17: 0}$ & - & - & 2.2 & - & - \\
\hline anteiso- $\mathrm{C}_{17: 0}$ & - & - & 3.8 & - & - \\
\hline \multicolumn{6}{|l|}{ Unsaturated } \\
\hline $\mathrm{C}_{17: 1} \omega 8 c$ & - & - & 2.3 & - & - \\
\hline $\mathrm{C}_{18: 1} \omega 6 c$ & 1.8 & - & - & - & - \\
\hline iso- $\mathrm{C}_{17: 1} \omega 9 \mathrm{c}$ & 2.4 & 2.8 & 3.3 & 5.7 & 13.2 \\
\hline \multicolumn{6}{|l|}{ Hydroxy } \\
\hline $\mathrm{C}_{15: 0} 2-\mathrm{OH}$ & 2.8 & - & 1.5 & - & - \\
\hline $\mathrm{C}_{15: 0} 3-\mathrm{OH}$ & 2.3 & - & - & 1.0 & \\
\hline iso- $\mathrm{C}_{15: 0} 3-\mathrm{OH}$ & 4.7 & 3.6 & 4.0 & 5.3 & 4.4 \\
\hline $\mathrm{C}_{16: 0} 3-\mathrm{OH}$ & 6.9 & 6.5 & 5.2 & 4.5 & 3.0 \\
\hline iso- $\mathrm{C}_{16: 0} 3-\mathrm{OH}$ & 3.0 & 2.2 & 2.2 & 4.3 & 1.3 \\
\hline $\mathrm{C}_{17: 0} 2-\mathrm{OH}$ & - & - & - & - & 1.7 \\
\hline $\mathrm{C}_{17: 0} 3-\mathrm{OH}$ & 1.3 & - & - & - & - \\
\hline iso- $\mathrm{C}_{17: 0} 3-\mathrm{OH}$ & 18.1 & 16.9 & 14.5 & 16.5 & 18.8 \\
\hline Summed feature ${ }^{\star}$ & 16.8 & 9.2 & 15.4 & 8.0 & 1.3 \\
\hline
\end{tabular}

${ }^{*}$ Comprising $\mathrm{C}_{16: 1} \omega 7 c$ and/or iso- $\mathrm{C}_{15: 0} 2-\mathrm{OH}$.

most closely to $M$. odoratimimus and $M$. profundi, but formed an independent phylogenetic line. Levels of $16 \mathrm{~S}$ rRNA gene sequence similarity between strain $\mathrm{JS}-08^{\mathrm{T}}$ and the type strains of $M$. odoratimimus and $M$. profundi were $97.0 \%$ (40 differences out of $1349 \mathrm{bp}$ ) and 96.8\% (43 differences out of $1349 \mathrm{bp}$ ), respectively, values that can be considered low enough for distinction at the species level.

Thus, the phylogenetic and phenotypic evidence presented indicates clearly that strain JS- $08^{\mathrm{T}}$ represents a novel species of the genus Myroides, for which the name Myroides marinus sp. nov. is proposed.

\section{Description of Myroides marinus sp. nov.}

Myroides marinus (ma.ri'nus. L. masc. adj. marinus of the sea, marine).

Cells are Gram-negative, aerobic, non-spore-forming, nonmotile, short rods (0.6-1.0 $\mu \mathrm{m}$ long and $0.2-0.3 \mu \mathrm{m}$ wide). Colonies are yellowish orange, circular and convex with entire margins on MA. The optimal temperature for

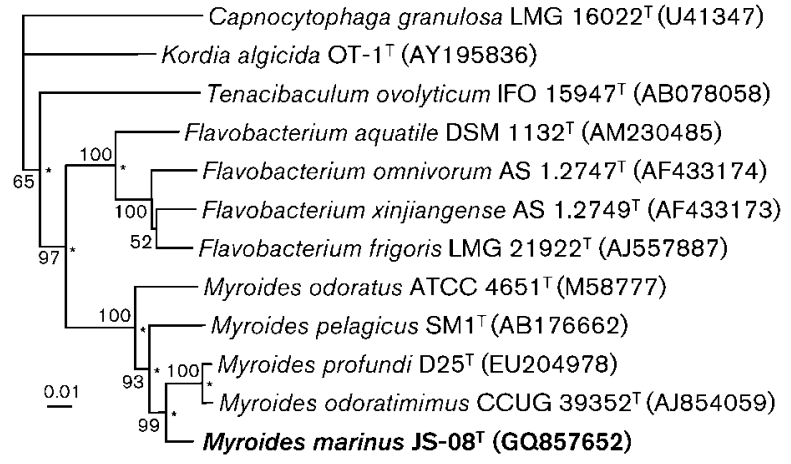

Fig. 1. Neighbour-joining tree (Saitou \& Nei, 1987) based on almost-complete $16 \mathrm{~S}$ rRNA gene sequences showing the relationship between strain $\mathrm{JS}^{-} 08^{\top}$ and the type strains of recognized Myroides species and other related species. Asterisks indicate branches that were also recovered by using the Fitch-Margoliash, maximum-likelihood and maximumparsimony algorithms. Numbers at nodes are levels of bootstrap support (percentages) based on a neighbour-joining analysis of 1000 resampled datasets by using Jukes-Cantor distances; only values $>50 \%$ are given. Bar, 0.01 substitutions per nucleotide position.

growth is $30{ }^{\circ} \mathrm{C}$. Growth occurs at $10-37{ }^{\circ} \mathrm{C}$ but not at 4 or $42{ }^{\circ} \mathrm{C}$. The $\mathrm{pH}$ range for growth is $\mathrm{pH} 5-9$, and optimal growth occurs at $\mathrm{pH} 6-7$. Growth occurs in the presence of $0-5 \% \quad(\mathrm{w} / \mathrm{v}) \quad \mathrm{NaCl}$ within 7 days. The predominant menaquinone is MK-6. The major fatty acids are iso$\mathrm{C}_{15: 0}$, iso- $\mathrm{C}_{17: 0} 3-\mathrm{OH}$ and a summed feature comprising iso- $\mathrm{C}_{15: 0} 2-\mathrm{OH}$ and/or $\mathrm{C}_{16: 1} \omega 7 c$. Catalase- and oxidasepositive. Voges-Proskauer test is positive. Citrate is utilized. Indole is produced weakly. Nitrate and nitrite are not reduced, and hydrogen sulphide is not produced. Hydrolyses DNA and Tweens 40 and 60, but not casein, cellulose, starch or Tweens 20 or 80 . Acid is not produced from amygdalin, arabinose, glucose, inositol, mannitol, melibiose, rhamnose, sorbitol or sucrose. As determined from API ZYM and API 20E strips, positive for alkaline phosphatase, acid phosphatase, esterase (C4), esterase lipase (C8), leucine arylamidase, valine arylamidase, cystine arylamidase, trypsin, $\alpha$-chymotrypsin, naphthol-AS-BIphosphohydrolase, gelatinase and urease activities, but negative for lipase (C14), $\alpha$-galactosidase, $\beta$-glucuronidase, $\beta$-galactosidase, $\beta$-glucosidase, $\alpha$-glucosidase, $N$-acetyl- $\beta$ glucosaminidase, $\alpha$-mannosidase, $\alpha$-fucosidase, arginine dihydrolase, lysine decarboxylase, ornithine decarboxylase and tryptophan deaminase. In Biolog GN2 microplates, the following compounds exhibit positive reactions: Tweens 40 and 80, succinic acid monomethyl ester, acetic acid, $\alpha$-hydroxybutyric acid, $\gamma$-hydroxybutyric acid, $\alpha$-ketobutyric acid, $\alpha$-ketovaleric acid, DL-lactic acid, propionic acid, succinic acid, bromosuccinic acid, L-alanine, L-alanyl glycine, L-asparagine, L-aspartic acid, L-glutamic acid, glycyl L-aspartic acid, glycyl L-glutamic acid, L-leucine, L-proline, L-serine, L-threonine, inosine, uridine and 
2,3-butanediol. The DNA G $+\mathrm{C}$ content of the type strain is $34.2 \mathrm{~mol} \%$.

The type strain, JS- $08^{\mathrm{T}}\left(=\mathrm{KCTC} 23023^{\mathrm{T}}=\mathrm{JCM} 16529^{\mathrm{T}}\right)$, was isolated from seawater collected off Boryeong Province, Chungnam, Republic of Korea.

\section{Acknowledgements}

This research was supported by the Project on Survey and Excavation of Korean Indigenous Species of the National Institute of Biological Resources (NIBR) under the Ministry of Environment, Korea, and also by a National Research Foundation of Korea grant funded by the Korean government (R01-2007-000-21120-0).

\section{References}

Bachmeyer, C., Entressengle, H., Khosrotehrani, K., Goldman, G., Delisle, F., Arlet, G. \& Grateau, G. (2008). Cellulitis due to Myroides odoratimimus in a patient with alcoholic cirrhosis. Clin Exp Dermatol 33, 97-98.

Bernardet, J. F., Nakagawa, Y. \& Holmes, B. (2002). Proposed minimal standards for describing new taxa of the family Flavobacteriaceae and emended description of the family. Int J Syst Evol Microbiol 52, 1049-1070.

Chen, X. L., Xie, B. B., Bian, F., Zhao, G. Y., Zhao, H. L., He, H. L., Zhou, B. C. \& Zhang, Y. Z. (2009). Ecological function of myroilysin, a novel bacterial M12 metalloprotease with elastinolytic activity and a synergistic role in collagen hydrolysis, in biodegradation of deep-sea high-molecular-weight organic nitrogen. Appl Environ Microbiol 75, 1838-1844.

Cho, S. H., Han, J. H., Ko, H. Y. \& Kim, S. B. (2008). Streptacidiphilus anmyonensis sp. nov., Streptacidiphilus rugosus sp. nov. and Streptacidiphilus melanogenes sp. nov., acidophilic actinobacteria isolated from Pinus soils. Int J Syst Evol Microbiol 58, 1566-1570.

Cui, Y. S., Im, W. T., Yin, C. R., Lee, J. S., Lee, K. C. \& Lee, S. T. (2007). Aeromicrobium panaciterrae sp. nov., isolated from soil of a ginseng field in South Korea. Int J Syst Evol Microbiol 57, 687-691.

Douce, R. W., Zurita, J., Sanchez, O. \& Cardenas Aldaz, P. (2008). Investigation of an outbreak of central venous catheter-associated bloodstream infection due to contaminated water. Infect Control Hosp Epidemiol 29, 364-366.

González, C. J., Santos, J. A., García-López, M. L. \& Otero, A. (2000). Psychrobacters and related bacteria in freshwater fish. J Food Prot 63, 315-321.

Green, B. T., Green, K. \& Nolan, P. E. (2001). Myroides odoratus cellulitis and bacteremia: case report and review. Scand J Infect Dis 33, 932-934.

Holmes, B., Snell, J. J. S. \& Lapage, S. P. (1977). Revised description, from clinical isolates, of Flavobacterium odoratum Stutzer and
Kwaschnina 1929, and designation of the neotype strain. Int J Syst Bacteriol 27, 330-336.

Källman, O., Lundberg, C., Wretlind, B. \& Ortqvist, A. (2006). Gramnegative bacteria from patients seeking medical advice in Stockholm after the tsunami catastrophe. Scand J Infect Dis 38, 448-450.

Kämpfer, P. \& Kroppenstedt, R. M. (1996). Numerical analysis of fatty acid patterns of coryneform bacteria and related taxa. Can $J$ Microbiol 42, 989-1005.

Kim, S. B., Lonsdale, J., Seong, C.-N. \& Goodfellow, M. (2003). Streptacidiphilus gen. nov., acidophilic actinomycetes with wall chemotype I and emendation of the family Streptomycetaceae (Waksman and Henrici $(1943)^{\mathrm{AL}}$ ) emend. Rainey et al. 1997. Antonie van Leeuwenhoek 83, 107-116.

Mammeri, H., Bellais, S. \& Nordmann, P. (2002). Chromosomeencoded beta-lactamases TUS-1 and MUS-1 from Myroides odoratus and Myroides odoratimimus (formerly Flavobacterium odoratum), new members of the lineage of molecular subclass B1 metalloenzymes. Antimicrob Agents Chemother 46, 3561-3567.

Maneerat, S., Nitoda, T. K., Kanzaki, H. \& Kawai, F. (2005). Bile acids are new products of a marine bacterium, Myroides sp. strain SM1. Appl Microbiol Biotechnol 67, 679-683.

Maneerat, S., Bamba, T., Harada, K., Kobayashi, A., Yamada, H. \& Kawai, F. (2006). A novel crude oil emulsifier excreted in the culture supernatant of a marine bacterium, Myroides sp. strain SM1. Appl Microbiol Biotechnol 70, 254-259.

Saitou, N. \& Nei, M. (1987). The neighbor-joining method: a new method for reconstructing phylogenetic trees. Mol Biol Evol 4, 406425.

Spiteller, D., Dettner, K. \& Bolan, W. (2000). Gut bacteria may be involved in interactions between plants, herbivores and their predators: microbial biosynthesis of $\mathrm{N}$-acylglutamine surfactants as elicitors of plant volatiles. Biol Chem 381, 755-762.

Thomas, M., Padmini, S. B., Govindan, V. K. \& Appalaraju, B. (2007). Oerskovia turbata and Myroides species: rare isolates from a case of acalculus cholecystitis. Indian J Med Microbiol 25, 297-298.

Vancanneyt, M., Segers, P., Torck, U., Hoste, B., Bernardet, J.-F., Vandamme, P. \& Kersters, K. (1996). Reclassification of Flavobacterium odoratum (Stutzer 1929) strains to a new genus, Myroides, as Myroides odoratus comb. nov. and Myroides odoratimimus sp. nov. Int J Syst Bacteriol 46, 926-932.

Yağci, A., Cerikçioğlu, N., Kaufmann, M. E., Malnick, H., Söyletir, G., Babacan, F. \& Pitt, T. L. (2000). Molecular typing of Myroides odoratimimus (Flavobacterium odoratum) urinary tract infections in a Turkish hospital. Eur J Clin Microbiol Infect Dis 19, 731-732.

Yoon, J. W., Maneerat, S., Kawai, F. \& Yokota, A. (2006). Myroides pelagicus sp. nov., isolated from seawater in Thailand. Int J Syst Evol Microbiol 56, 1917-1920.

Zhang, X. Y., Zhang, Y. J., Chen, X. L., Qin, Q. L., Zhao, D. L., Li, T. G., Dang, H. Y. \& Zhang, Y. Z. (2008). Myroides profundi sp. nov., isolated from deep-sea sediment of the southern Okinawa Trough. FEMS Microbiol Lett 287, 108-112. 